\title{
Avant-Garde Research in the Field of Verse Forms (based on I. Yuzeev lyrics)
}

\section{[Авангардные поиски в области форм стиха (на материале лирики И. Юзеева)]}

\author{
Daniya F. Zagidullina - Venera R. Amineva
}

\section{DOI: $10.18355 / X L .2016 .09 .01 .135-145$}

\begin{abstract}
Аннотация
В статье раскрываются структурно-содержательные особенности особой формы стиха, которая складывается в творчестве татарского поэта И.Юзеева. Эта форма стиха отражает художественно-эстетическую природу авангардных поисков, характерных для татарской поэзии 1960-1980-х гг. Выявлена роль повторяющейся мысли-строки в создании композиционного и стилистического ритма в стихотворениях поэта. Установлено, что мифопоэтический язык и язык тропов, восходящие к народной поэзии, подвергаются внутренним трансформациям, становясь более сложными, индивидуальными и непредсказуемыми. Определяется основной тип субъектной ситуации,
\end{abstract} присущий лирике татарского поэта.

Ключевые слова

татарская поэзия, жанр, дейксис, параллелизм, кумуляция, неосинкретизм, ритм

\section{Введение}

В татарской поэзии 1960-1980-е годы - время изменений литературных ориентиров и парадигм, период трансформации литературно-эстетических особенностей национальной литературы под влиянием авангардных экспериментов и поисков. «Ее развитие в несколько ином направлении по сравнению с более ранним периодом, стремление к новому в философском и художественном осмыслении, к выходу за идеологические рамки литературы, приоритетом которой были общественные законы, объясняется раскрытием новых сторон образного восприятия мира и бытия» (Galiullin, Iuosypova, 2007: 4).

Актуальность исследования определяется необходимостью теоретического осмысления той роли, которую сыграл авангард в обновлении татарской литературы 1960-1980-х гг., в возвращении к национальным традициям модернизма начала XX века. Татарская литература данного периода и ее основные направления в той или иной мере изучены литературоведами (Zagidullina, Iusupova, 2011; Galiullin, 2008; др.), но до сих пор не было специальных исследований, посвященных исследованию авангарда в татарской литературе XX века. До сих пор не определены роль и значение авангардных поисков для развития татарской литературы в целом. Нет специальных исследований, раскрывающих содержание и объем понятия «авангард» применительно к национальному историко-литературному процессу.

Авангардные эксперименты занимают важное место в творчестве известного татарского поэта И.Юзеева, пришедшего в литературу в 1950 -е гг. и развивавшего прежде всего классические поэтические традиции. Начиная с 1965 г. в лирике поэта складывается новая концепция мира и человека. Изменяется предмет изображения: «Мир, окружающий лирической героя, воспринимается как часть земного шара, часть Вселенной, поэт чувствует единство прошлого, настоящего и будущего, ритм Вселенной и времени» (Nigmatullina, 1983: 39). 
Лирический герой выступает как представитель не только своего рода, нации, но и всего человечества - это обобщенное, почти символическое «я». Вступая в своеобразный диалог с традициями модернизма начала XX в. (Zagidullina, 2013), И.Юзеев ищет свои пути обновления татарской поэзии, оказавшейся в годы застоя в жестких границах соцреализма. Большое влияние на поэта оказывает философия и эстетика экспрессионизма. Стремление к открытой эмоциональности, интенсивность, динамичность чувств и средств их художественного воплощения, напряженность поэтической интонации, тяготение к абстрактному обобщению приводят к выработке новых принципов организации стихотворной речи.

Творчество И.Юзеева достаточно изучено в литературоведении в разных аспектах: с точки зрения идейно-тематического своеобразия его творчества, сквозных образов и мотивов, жанровой системы его поэзии (Hösni, 1974; Möhämmädiev, 1980; Mustafin, 1981; Möhämmädiev, 1983; Galiullin, 1985; Dautov, 2002; Vəliev, 2003; Galiullin, 2003; Galiullin, 2008; Iusupova, 2014). Однако вне сферы внимания ученых оказались используемые поэтом формы стиха, их субъектная архитектоника, структура словесного образа, композиция.

\section{Методика}

В решении поставленных задач предполагается использование системноструктурного метода, который реализуется в подходе к анализу отдельного произведения как целостной художественной системе, в которой создается относительно завершенный образ мира, воплощающий определенную эстетическую концепцию действительности (Leiderman, 2010: 17 - 143).

Структурный подход требует различать в любом культурном феномене два уровня: 1) явный, или «поверхностный», данный в непосредственном наблюдении, и 2) неявный, или «глубинный», собственно структурный. Эти уровни и соотношение между ними раскрывается в процессе имманентного исследования текста (Bart, 1994).

Исследование форм стиха в лирике И.Юзеева проводится с опорой на работы, посвященные смыслообразующей роли компонентов стиховой формы (Lotman, 1996; Fedotov, 2003; Etkind, 1998).

На концепцию проводимого исследования оказали влияние труды, в которых раскрываются особенности субъектной организации лирического произведения (Ginsburg, 1997; Corman, 2006; Broytman, 2008).

Предполагается решение поставленных задач с помощью сравнительнотипологического и сопоставительного методов исследования. «So, the comparative analysis of literary works belonging to different national literatures helps to understand how the universals of word art work and how literature's national identity can be realized. Such notions as context, process and event are highlighted in this analysis» (Amineva, 2014: 2097) ${ }^{1}$. Одной из задач сравнительного и сопоставительного исследования национальных литератур является выявление

1 Таким образом, понять функционирование универсалий словеснохудожественного искусства и пути реализации национальной идентичности литературы помогает сопоставительный анализ произведений, принадлежащих разным национальным литературам, - анализ, в котором усилены моменты контекстуальности, процессуальности, событийности; используются дескриптивные и нарративные, логико-дискурсивные и образнометафорические способы познания. Подстрочный перевод выполнен В.Р.Аминевой. 
национальной специфики художественного текста. Понять национальную идентичность литературы помогают характерные для нее процедуры смыслопорождения: "Tatar writers have a concrete moral and ethic goal and build the verbal-ideological world of a literary work from a "high hierarchical position" (M.M. Bakhtin). The main idea is objectified with the help of various relations of "pointing out the meaning" $<\ldots>$ The monologic concentration of characters on their emotional state and self-determination in Tatar literature is contrasted with the dynamic contentious model of events and dialogues inherent in the dramatic concept of Russian novel in the second half of $19^{\text {th }}$ century" (Amineva, 2014: 2096-2097) ${ }^{1}$. Также востребованными являются межкультурные подходы, результативность которых выявлена в работах Я.Бировой (Birova, 2013, 2; Birova, 2013, 3).

Предметом анализа в данной статье является ряд стихотворений, представляющих разные тематические сферы творчества И.Юзеева, отобранных по признаку наивысшей художественной ценности и наибольшей характерности для творческой манеры поэта

\section{Авангардные поиски}

В творчестве И.Юзеева складывается особая форма стиха, получившая название «юзеевской» и впоследствии усвоенная другими татарскими поэтами. Она типологически сходна с жанром философских определений, которые вслед за В.Соловьевым в русскую поэзию ввел Б.Пастернак. В книгу «Сестра моя жизнь» (1922) включены «Определение поэзии», «Определение души», «Определение творчества» (см.: Jensen, 1997; O’Connor, 1988). Как и Б.Пастернак в «Определении поэзии», И.Юзеев в стихотворениях «Моя душа бескрайний темный лес» (1966), «На все восторженно гляжу» (1967), «Скажите, из чего зародилась душа» (1964), «Тревога» (1971) и др. обращается к форме дейксиса ${ }^{2}$. Идея об участии дейксиса в процессах текстообразования не нова (Fillmore 1966; Gathercole 1977; Gathercole, 1979).

Так, в стихотворении «Моя душа - бескрайний темный лес» душа определяется татарским поэтом через предметный план, представленный образами природы. Складывается образная структура, которая восходит к фольклорному параллелизму, «имманентный язык которого заставляет воспринимать возникающую картину не как поэтическую условность, а как

1 Татарские писатели преследует конкретную морально-этическую цель и выстраивает словесно-идеологический мир произведения с "иерархической позиции высоты” (М.М.Бахтин). Главная мысль объективируется с помощью разнообразных отношений “указания на смысл” <..> Монологическая сосредоточенность героев на своих переживаниях, эмоциональном самосознании и самоопределении в произведениях татарских авторов противопоставлена динамической конфликтной модели характера, активности событийных и диалогических рядов, определяющих специфику концепции драматического в русском романе 2-й половины XIX в. Подстрочный перевод выполнен В.Р.Аминевой.

2 Форма дейксиса придает «определению» характер «внешнего указательного жеста, направленного на именуемый предмет» и оживляет архаический тип идентификации явлений и его имени, так называемый «биноминативный» тип синтаксической структуры, «где между определяемым и определяющей экспликацией нет отношения подчиненности, т.е. в собственном смысле нет акта предикации, и действует закон полной тождественности» (Khan, 2001: 175, 176). 
бытийную реальность, имеющую одновременно и самый буквальный, и самый универсальный смысл» (Broytman, 2008: 214). С дейксисом в стихотворениях И.Юзеева связан и особый способ восприятия себя и мира, восходящий к сплошному перечислительно-сочинительному ряду кумуляции, в котором характеристики, относящиеся к лесу и к человеческой душе, выступают нерасчлененно. Соответственно душа и «бескрайний темный лес» образуют не разные, а одну синкретическую реальность.

Принципиальная множественность формулировок - определений состояний души - такова, что каждая из них, выделяя что-то отдельное и конкретное ${ }^{1}$, характеризует душу лирического «я» в целом. Между единичным и единым, индивидуальным и всеобщим устанавливаются взаимно-однозначные соответствия. Движение темы идет в направлении от конкретизированного перечисления состояний природных явлений, стремящегося к непосредственному совпадению высказывания с его предметом, к обобщенному изображению души «изнутри» - через ее интенцию. Мотив «бескрайнего темного леса» как эквивалента души трансформируется в финале стихотворения в сторону своей самой глубокой сущности - способности все вытерпеть, выдержать и сохранить неизменную устремленность к небу, солнцу, свету: «Душа моя - бескрайний темный лес: / утратит надежду, / вытерпит, выдержит... / Только на солнечную дорогу выйдет...» (Iuzeev, 1982: 52)2.

Композиционной основой рассматриваемых стихотворений является прием повторов. Повтор основного тезиса определяет переход от композиционных форм к архитектоническим (см. об этом: Johnson, 1982). В стихотворении «Душа моя - бескрайний темный лес...» природный и душевный ряды даются вначале в их невыделенности и, казалось бы, случайном следовании друг за другом: «Душа моя - бескрайний темный лес: / шумит, успокаивается, / стремится вверх, ломается, поет, смеется, / рождается, умирает...». И только в финальных двух строчках душевный ряд, на всем протяжении стихотворения многолинейно перекрещивающийся с природным, выходит на первый план: «Душа моя - бескрайний темный лес: / утратит надежду, / вытерпит, выдержит... / Только на солнечную дорогу выйдет...» (Iuzeev, 1982: 52), позволив констатировать превосходство внутреннего состояния индивида над внешними обстоятельствами.

Парадигматическое соположение изоморфных определений во 2 и 4 строках подчиняется принципу антитезы: шумит - успокаивается; рождается умирает. Семантическая композиция остальных строк выстраивается по принципу «ризомы» с характерными для нее несистемными и неожиданными связями и отношениями: «ищет, находит, воспаряет в небо, любит, сходит с ума, стонет...». Глаголы, характеризующие состояние человеческой души, содержат две интенции - страдательную («стонет», «утратит надежду») и активносозидательную («ищет», «находит», «воспаряет в небо», «любит», «вытерпит», «выдержит», «выйдет»). Явный перевес второй интенции определяет оптимистически-мажорный тон стихотворения.

${ }^{1}$ Возникает перекличка с таким явлением немецкой и русской литератур, как конкретизм. Стоящий у истоков этого течения О.Гомрингер пишет: «Мы должны давать только обнаженные слова, без грамматических связей, без отвлеченных понятий, слова, обозначающие либо конкретные действия, либо конкретный предмет» (Kylakov, 1999: 98).

2 Здесь и далее - подстрочный перевод наш. 
Стихотворение «На все восторженно гляжу...» (1967) воспроизводит характерные особенности юзеевского высказывания. Перед нами своеобразный каталог образов, последовательность которых определяется принципами построения художественного мира как особого рода синкретического целого. Стихотворение состоит из трех частей, структурированных повторяющейся строкой: «На все восторженно гляжу...». В первой и второй частях взгляд лирического героя, направленный вокруг, вдаль, вверх, подчиненный смене расширений и сужений поля зрения, представляет мир в его целостности и нерасчлененности. Конкретные образы: тополь, луна, жеребенок, волна, цветок, зола - чередуются с обобщенными: осень, рассветы, плачущие берега.

В одних определениях, передающих состояние природы, заключена динамика («быстрая волна», «увядший цветок», «потухшая зола»), другие фиксируют типический, повторяющийся признак предметов и не индивидуализируют, а обобщают их - «золотая осень», «кудрявый тополь», «грустные рассветы», «плачущие берега». В стихотворении происходит постепенная интериоризация изображенного мира - объекты наблюдения и оценки превращаются в субъекты переживаний и действий: «приветливая луна», «веселый жеребенок», наконец, плачущие берега, которые «машут мне вслед».

Образному ряду соответствует смена эмоционально-смысловой перспективы. С оптимистическим эмоциональным настроем первой части стихотворения контрастируют мотивы увядания, угасания, грусти, слез во второй части. По этому же принципу соотносятся последние строки первой и второй строф: «Словно вижу в первый раз» и «Словно вижу в последний раз». В третьей строфе, синтезирующей противоположные душевные состояния и переживания, возникают две точки зрения и два связанных с ними контрастных ценностно-смысловых кругозора: «Я словно новорожденный ребенок, / Я словно убитый на войне брат». Эти голоса и интенции (новорожденного ребенка и убитого на войне брата) неслиянны и в то же время нераздельны, потому что каждый говорит от первого лица. Открытость и текучесть субъектной ситуации указывает на существование двух голосов внутри «я», совмещение двух взаимоотрицающих, но и не существующих друг без друга позиций человека в мире. Их объединяет жажда познания и восторг перед неизведанным.

В стихотворении «Из чего зародилась душа?» (1964) лирический субъект отстраняет от себя содержание души и рассматривает ее как внеположный предмет высказывания, подлежащий «объектному познанию» путем многоступенчатого определения. Создается метафорически кумулятивная цепочка, в которой сталкиваются и пересекаются явления, принадлежащие разным семантическим рядам. Этот ряд воспроизводит хаотическое состояние смешения разнородных свойств и качеств, из которых зародилась душа: это и макро- и микрокосм, звук, цвет и вкус, стихии огня, воды, воздуха и земли.

Природа в ее космических проявлениях (в грозе, буре и др.) и в ее предметах и частностях (облако, камень, конский волос) воплощает представление о мире как о живом, разнообразном, движущемся целом. Каждый из образов семантически эквивалентен другому и вносит в кумулятивную цепочку свои смысловые оттенки. Таким образом, одно из определений души лирический субъект стихотворения ищет в глубинных закономерностях природных процессов и явлений. Развертывается символический параллелизм, отождествляющий контуры воссоздаваемого в стихотворении макрокосма со структурой человеческой души. Ее сверхличное существование связано с вечной пульсацией живой жизни, не поддающейся описанию с личносубъективной точки зрения.

В третьей строфе душа познается через составляющие ее чувства и вкусы. Рядоположенные образы содержат противоположные интенции: любви и 139 
ненависти, радости и горя, горечи и сладости. Целое души - результат действия этих взаимоисключающих начал. Смысловая связанность и глубина перекрестных взаимодействий усиливается в четвертой строфе, где душа характеризуется через вкус, звук, эхо, узор, ощущение, цвет. Каждое из определений, будучи самостоятельным, не может быть понято без другого.

Между строками, включающими в себя завершенные вопросительные синтаксические конструкции, отсутствуют иерархические связи подчиненности ни в причинно-следственном, ни в пространственном, ни во временном отношениях. Связь образов восходит к архаическому синкретическому образному ряду соположения, кумулятивного накопления. Смысловые цепочки, данные вперемежку, образуют знакомое нам по другим произведениям И.Юзеева символическое рядоположение. С самого начала стихотворения поэт ведет несколько пересекающихся тем, обозначающих разные сферы и интенции души - природно-физическую, чувственно-витальную, психическиэкзистенциальную, которые образуют синкретическое единство.

Стихотворение сочетает две тенденции: во-первых, кумулятивный ряд образов раскрывает природу и сущность человеческой души, во-вторых, воссоздается сама история души, процесс ее рождения. Многолинейная семантическая цепь, используемая для определения души, начинает функционировать и как ее всеобщий метаязык, который углубляет смысловую перспективу стихотворения и лично-субъективную позицию говорящего. Он выступает как «другой» по отношению к душе. Став на точку зрения «души», на ее метаязыке и строит свое высказывание лирическое «я», пытаясь создать образ души. Этим обусловлена внутренняя диалогичность стихотворения. Возникает субъектный неосинкретизм - два субъекта («я» и «душа») выступают как нераздельные и неслиянные.

В своем опыте определения души И.Юзеев продолжает традиции татарских поэтов начала XX в., прежде всего Г.Тукая, который наделяет душу самостоятельным бытием, отражающим характерное для восточного сознания представление о ее материализованности и субстантивированности. Так, в стихотворении «Надежда» (1908) «смысловое взаимодействие эпитетов создает психологический контекст, раздвигающий семантические пределы образа души. Они выявляют и закрепляют преобладание в лирике Г.Тукая объективного плана в образе-концепте «душа» над субъективным, индивидуализированным...» (Amineva, 2012: 8)

В данном произведении И.Юзеева утверждение, завершающее цепь вопросительных конструкций, содержит оксюморон: «Сердце размером с листочек / Смогло вобрать в себя тысячи свойств земли» (Iuzeev, 2012: 27). Понимание души (сердца) как листа, сумевшего вобрать в себя тысячи свойств земли, трансформирует предшествующий бытийный план слов и образов в метафорический. С образом сердца как листа в стихотворение входит мифологическая семантика 1, открывающая в душе новые стороны. Душа наделяется чертами, обнаруживающими в ней дополнительность многообразных начал - активного и страдательного, статичного и динамичного, устойчивого и изменчивого, прочного, твердого и хрупкого и др.

И.Юзеев использует данную форму стиха, обращаясь не только к философской, но и к социокультурной, национально-исторической, любовнопсихологической проблематике. Стихотворение «Нет, я не могу так жить...»

${ }^{1}$ Согласно мусульманскому учению, судьба каждого человека написана на листе дерева, растущего у трона Аллаха. 
(1970) отражает процесс самосознания и самоопределения лирического героя. Свою жизненную позицию он противопоставляет неприемлемой для него позиции «другого». Конфликт двух ценностно-смысловых кругозоров отражается в жестком параллелизме как основной закономерности построения текста.

Мотив горения, выражающий состояние высшего напряжения, воодушевления и энтузиазма духовной жизни, многократно усиливается указанием на действие («Сам разожгу костер...») и плеоназмом («горю, пылаю» (Iuzeev, 1982: 40)). Этот мотив противопоставляется стремлению согреться у чужого костра, «прислонить спину к печи» (Iuzeev, 1982: 40).

Жизненную позицию лирического героя раскрывают мотивы активного отношения к жизни, способности оставаться самим собой, невозможности жить без Неба, Солнца, быть в своих помыслах и устремлениях равновеликим мирозданию, противопоставленные покорности обстоятельствам, умению «плыть по течению», готовности склонить голову перед сильным, быть рабом судьбы. Возникает своеобразная космогония, основными действующими лицами которой являются Судьба, Солнце, Небо, Земля, лирическое «Я». В сознании поэта утверждается связь человека и мироздания как двух единоприродных существ, разделяющих бытие и состояние друг друга: «Нет, я не покину Землю,- /Что она будет делать без меня?!» (Iuzeev, 1982: 40).

Стихотворение состоит из 4 частей. Первая и третья строфы включают по три строки и представляют собой концентрированное изложение точки зрения и слова «другого». Вторая и четвертая строфы объединяют два идеологических полюса. Неприемлемый эталон поведения опровергается авторским контекстом, несущим могучую личностную энергию и огромную силу духовного порыва.

Стихотворение «Любовь, что ты сделала со мною?» (1971) построено как последовательный ряд изменений, происходящих как в душе лирического героя, так и в окружающем его мире. Смысловая общность элементов этой цепи обусловлена тем, что все они являются разнообразными вариантами одного изначального типа события - преображения, исчезновения из обычной жизни и воскресение в ином плане бытия в качестве существа иной природы. Лирический герой оказывается страдательным лицом, объектом, испытывающим воздействие некой внеположной ему могучей силы. Субъектом действия, вызывающим метаморфозы, выступает любовь. Кумулятивный ряд образуют глаголы, обладающие противоположной интенцией («разожгла, погасила»), либо одной и той же, но усиленной повторением («свела с ума, взбесила»), либо устанавливающие причинно-следственные отношения («сжигала - сделала пеплом», «заставила слушать - убедила», «во время разлуки научила терпеть» (Iuzeev, 1982: 44)).

В строках смешиваются образы, принадлежащие разным рядам, связанные между собой отношениями дополнительности и раскрывающие сложность жизни, любви и рефлексии лирического героя: зрительные («обратила взор к звездам»), слуховые («заставила слушать»), двигательные («заставила плясать», «заставила срывать цветы»), природно-космические в их проекции в план человеческого бытия («Ночь превратила в день, / День превратила в ночь»), относящиеся к физически-витальной сфере человеческой экзистенции («обновила чувства», «свела с ума...») и к духовному переживанию и познанию («пробудила тоску», «устремила к небесам», «утончила душу»), разрушительные («превратила в пепел») и жизнесозидательные («обогатила душу» и др.) (Iuzeev, 1982: 44). Таким образом воссоздается состояние влюбленного человека, в котором все нерасчленимо и взаимообусловлено.

Стихотворение интересно своей архитектоникой. Герой максимально растворен в изображаемом событии любви и имманентен ему. Перед нами 141 
взгляд на себя извне, как на «другого», и из иного состояния мира. Избранная форма высказывания служит апологии возвышенного чувства любви.

\section{Заключение}

«Юзеевская строфа», основанная на повторах, будучи формой свободного стиха, наиболее органично отражает художественно-эстетическую природу авангардных явлений в татарской литературе 1960-1980-х гг. Складывается представление о том, что картина мира зафиксирована в обобщенном тезисе, мысли о бытии, которая постепенно раскрывается на разных структурных уровнях произведения, связанных с метром, эвфонией, композицией и стилем, и имитирует процесс разрастания точки, расширения сферы первоначального точечного восприятия. С повторяющейся мыслью-строкой связаны звуковой, композиционный и стилистический ритм в стихотворениях татарского поэта. Мотивируя лексический ряд, она определяет и принципы соединениясопоставления слов-образов.

Разные начала и сферы бытия, которые обладают принципиально разным содержанием и разной ценностью, оказываются в отношениях дополнительности, взаимно-однозначных соответствий, противопоставления, взаимообусловленности и взаимопроникновения. Так создается синкретичная образная система, отражающая представление о единстве и целостности бытия. Этот мир обладает самоценностью и в то же время является реальностью авторской интенции. Между миром и «я» устанавливается соответствие.

Лирический субъект И.Юзеева отождествляется с эмпирическим субъектом как индивидуальным носителем сознания. Вместе с тем этот субъект выступает и как носитель родового сознания народа, нации, человечества, и как «я», связанное с «другим», с «мы» субъектными отношениями изначальной сопричастности изображенного лирического события некоей высшей целесообразности. И.Юзеев, раскрывая процесс самоидентификации лирического героя, продолжает традиции татарской поэзии начала XX вв. прежде всего Г.Тукая. В стихотворении «Национальные мелодии» (1909) «лирический герой Г.Тукая, исполнитель песни “Аллюки”, и народ, сложивший ее, образуют особую субъектную целостность, которая отличается такими чертами, как нераздельность “я” и “другого”, “я” и “мы”, отсутствие между ними субъектных границ» (G.Tukay's poetry: the aspects of national identity, 2015: 81).

На примере авангардных поисков И.Юзеева можно констатировать, что новые явления в татарской поэзии 1960-80-х гг. появились на фоне возрожденного романтизма и непрерывности традиций модернизма (экспрессионизма). Эта особенность перекликается с выводом, к которому приходит исследователь поэзии немецких экспрессионистов Г.Мартенс, который рассматривает их как прямых наследников классики и романтизма, руководствующихся способами выражения, позаимствованными у всей духовной истории (Martens, 1979).

\section{Выводы}

Сложившаяся в творчестве И.Юзеева форма стиха характеризуется следующими особенностями:

- В качестве способа идентификации предмета используется дейксис, определяющий формально-содержательные особенности произведения.

- «Определения» связаны между собой простым рядоположением и изоморфностью синтаксических структур.

- Каждое из «определений» самостоятельно, но не существует вне целого. 
- Создаваемый поэтом художественный мир оказывается особого рода синкретическим целым и характеризуется нерасчлененностью природного и душевного рядов, недифференцированностью свойств, признаков, явлений.

- Принципы «соответствия» определений друг другу (семантической эквивалентностью) и их кумулятивного накопления ведут к расширению значения и переключению планов. Определения связаны между собой не метафорическими и не метонимическими, а символическими соответствиями.

\section{Bibliograpic references}

AMINEVA, V.R. 2014. "Universal" and "Unique" as the Categories of Comparative Literature. In: Middle-East Journal of Scientific Research, n. 20 (12), pp. 2094-2098. ISSN 1990-9233

AMINEVA, V.R. 2012. M.Iu.Lermontov i G.Tukai: k voprosu o strukturnosoderzhatel'nykh osobennostiakh mezhliteraturnykh tekstovykh obrazovanii. In: Filologiia i kul'tura, n. 2 (28), pp. 7-10. ISSN 2074-0239

BART, R. 1994. Izbrannye raboty: Semiotika. Poetika / per. s fr. / Sost., obshch. red. i vstup. st. G.K.Kosikova. M.: Progress. Univers. 615 p. ISSN 5-01-004408-0

BIROVA, J. 2013. About Theoretical Definitions of Pluralistic and Pluricultural Approaches. In: XLinguae, European Scientific Language Journal, vol 6, issue 2, 2013, pp. 91-103. ISSN 1337-8384

BIROVA, J. 2013. Pluralistic and pluricultural approaches intuitively applied by teachers of French. In: XLinguae, vol. 6, no. 3, pp. 76-100. ISSN 1337-8384

BROYTMAN, S.N. 2008. Broitman S.N. Poetika russkoi klassicheskoi i neklassicheskoi liriki. M.: RGGU. 485 p. ISSN 978-5-7281-0911-2

G.Tukay's poetry: the aspects of national identity / V.R. Amineva, M.I. Ibragimov, E.F. Nagumanova, A.Z. Khabibullina. In: XLinguae European Scientific Language Journal, vol 8, issue 1, pp. 79-87. ISBN 1337-8384

CORMAN, B.O. 2006. Izbrannye trudy. Teoriia literatury. Izhevsk: In-t komp'iuternykh issledovanii. 552 p. ISSN 5-93972-516-3

DAUTOV, A.I. 2002. Ildar Yuzeev shigriyatendä romantism. Kasan: "Intelpress". $152 \mathrm{p}$.

ETKIND, E.G. 1998. Materiia stikha. SPb.: Izd-vo "Gumanitarnyi soiuz". 508 p. ISSN 0078-9976, ISBN 2-7204-0213-3, ISBN 5-89867-001-7

FEDOTOV, O.I. 2003. Osnovy teorii literatury: v 2 ch. M.: Gumanit. izd. tsentr VLADOS. Ch. 2: Stikhoslozhenie i literaturnyi protsess. 240 p. ISBN 5-691-01138-3, ISBN 5-691-01140-5 (II)

FILLMORE, C.H. 1966. Deictic categories in the semantics of come. In: Foundations of Language, n. 2, pp. 219-227. ISSN 0015900x

GALIULLIN, T. N. 2003. Shigriyat ofyklary. In: Tatar shigriyate: 1980-2000 ellar. Kasan: Mägarif, pp. 4-30. ISBN 978-5-7761-1726-8

GALIULLIN, T. 1985. Shagyyrlär häm shigyrlär. Kasan: Tatarskoje knizhnoje izdatel'stvo.

GALIULLIN, T. 2008. Shigriyattä öz bieklege bar! In: Il'dar Yuzeev: istäleklär, äңgämälär, shigyrlär. Kasan: Tatarskoje knizhnoje izdatel'stvo, pp. 172-176.

GALIULLIN, T., IUOSYPOVA, N. 2007. Basynky ellarnyy därtle shigriyate. In: Tatar shigriyate: 1960-1980 ellar. Kasan: Mägarif, pp. 3-26. ISBN 978-5-7761-17268

GATHERCOLE, V. 1977. Study of the Comings and Goings of the Speakers of Four Languages: Spanish, Japanese, English and Turkish. In: Kansas Working Papers in Linguistics, vol. 2, pp. 61-94. ISSN 1043-3805

GATHERCOLE, V. 1979. Towards a Universal for Deictic Verbs of Motion. In: Kansas Working Papers in Linguistics, 1979, vol. 3, pp. 72-88. ISSN 1043-3805 GINSBURG, L.J. 1997. O lirike. M.: Intrada, 408 s. ISSN 5-87604-037-1

143 
KHAN, A. 2001. Poeticheskaia vselennaia. Analiz stikhotvoreniia B.Pasternaka «Opredelenie poezii»: predvaritel'nye itogi $\mathrm{k}$ analizu tsikla «Zaniat'e filosofiei». In: Studia Russica XIX. Budapesht, pp. 169 - 188. ISSN 0139-0287

HÖSNI, F. 1974. Ujna, ujna monly sazym: shagyyr I.Yuzeev portretyna kajber shtrihlar. In: Ni äitergä? Nichek ätergä? Kasan: Tatarskoje knizhnoje izdatelstvo, pp. 190-196.

JENSEN, P.A. 1987. Boris Pasternaks “Opredelenie poesii”. In: Text and Context. Essay to Honor Nils Ake Nilsson. Stockholm, pp. 96-111. ISSN 10: 9122008799, ISBN 13: 9789122008798

JOHNSON, W.R. 1982. The idea of lyric. Berkley and Los Angeles: University of California Press. 214 p. ISSN 0-520-04462-2

KYLAKOV, V. 1999. Poeziia kak fakt. Stat'i o stikhakh. M.: Novoe literaturnoe obozrenie. 400 p. ISSN 5-86793-039-4

LEIDERMAN, N.L. 2010. Teoriia zhanra: Nauchnoe izdanie / Institut filologicheskikh issledovanii i obrazovatel'nykh strategii «Slovesnik» UrO RAO; Ural. gos. ped. un-t. Ekaterinburg. ISBN 978-5-904205-04-1

LOTMAN, Iu.M. 1996. O poetakh i poezii: Analiz poeticheskogo teksta: Stat'i i issledovaniia. Zametki. Retsenzii. Vystupleniia. SPb.: Iskusstvo-SPB. 848 s. ISBN 5210-01487-8

MARTENS, G. 1978. Nietzsches Wirkung im Expressionismus. In: Nietzsches und die deutsche literature. Tubingen, pp. 35-82.

MÖHÄMMÄDIEV, R. 1980. Yazgy his. In: R.Möhämmädiev. Ägär bes yanmasak. Kasan: Tatarskoje knizhnoje izdatelstvo, pp. 35-41.

MÖHÄMMÄDIEV, R. 1983. Yze tanysh, yze yana mon. In: R.Möhämmädiev. Yakutlar tabyladyr vakyt belän. Kasan: Tatarskoje knizhnoje izdatelstvo, pp. 96-106.

MUSTAFIN, R. 1981. Solov'i priletaiut poodinochke. In: Mustafin R. Obraz vremeni. Kazan', pp. 264-272.

NIGMATULLINA, Iu.G. 1983. Metodologiia kompleksnogo izucheniia khudozhestvennogo tvorchestva. Kazan': Izd-vo Kazanskogo un-ta, 102 p.

O'CONNOR, K.T. 1988. Boris Pasternak's "My sister - Life". The Illusion of Narrative. Ann Arbor. 306 p. ISBN 0882337785, 9780882337784

VӘLIEV, M. 2003. Shagyyr nigä kartaymy? In: Gamäl däftäre. Kasan: Mägarif, pp. 259 - 272. ISBN 5-298-01305-8

IUSUPOVA, N.M. 2014. Iuzeev I.G. In: Tatarskaia entsiklopediia: V 6 t. Kazan': In-t tatarsk. entsiklopedii AN RT, t. 6, p. 475. ISBN 978-5-902375-11-1

IUZEEV, I. 1982. Mähäbbät kitaby: shigyrlär, žyrlar, poemalar. Kasan: Tatarskoje knizhnoje izdatelstvo.

IUZEEV, I. 2012. Mänge yang kyyel: shigyrlär, жyrlar, balladalar, poema. Kazan': Tatar. kn.izd-vo. ISBN 978-5-298-02324-5

ZAGIDULLINA, D.F. 2013. Modernizm v tatarskoi literature pervoj treti XX veka. Kazan': Tatar. kn.izd-vo. ISBN 978-5-298-02500-3

ZAGIDULLINA, D.F., IUSUPOVA, N.M. 2011. Tatarskaia literature XX veka: v 2 kn. Kniga 2. Kazan': Izd-vo Kazan. un-ta. ISBN 978-5-98180-956-9

Работа выполнена при финансовой поддержке РГНФ (проект № 14-14-16002).

Words: 3708

Characters: 29814 (16, 56 standard pages)

Prof., academician Daniya F. Zagidullina, Doctor of Philology, Academy of Sciences of the Republic of Tatarstan

Bauman st., 20.420008, Kazan, 
Republic of Tatarstan, Russia zagik63@mail.ru

Assoc. Prof. Venera R. Amineva, Doctor of Philology,

Department of Russian literatry and methods of teaching Kazan Federal University

18, Kremlyovskaya St., 420008 Kazan

Republic of Tatarstan, Russia

amineva1000@list.ru 